\title{
The cooperation between professional societies contributes to the capacity building and system development for prevention and control of cancer in low- and middle-income countries: the practice of Cervical Cancer Prevention and Control Project in Cambodia
}

\author{
Koum Kanal ${ }^{1}$, Noriko Fujita ${ }^{2,3, *}$, Sann Chan Soeung ${ }^{1}$, Kruy Leang Sim $^{4}$, Yasuyo Matsumoto ${ }^{3}$, Rei Haruyama ${ }^{2,3}$, \\ Kouji Banno ${ }^{3,5}$, Tadashi Kimura ${ }^{3,6}$ \\ ${ }^{1}$ Cambodian Society of Gynecology and Obstetrics, Phnom Penh, Cambodia; \\ ${ }^{2}$ Bureau of International Health Cooperation, National Center for Global Health and Medicine, Tokyo, Japan; \\ ${ }^{3}$ Japan Society of Obstetrics and Gynecology, Tokyo, Japan; \\ ${ }^{4}$ Undersecretary of States, Ministry of Health, Phnom Penh, Cambodia; \\ ${ }^{5}$ Department of Obstetrics and Gynecology, Keio University School of Medicine, Tokyo, Japan; \\ ${ }^{6}$ Department of Obstetrics and Gynecology, Osaka University Graduate School of Medicine, Osaka, Japan.
}

\begin{abstract}
Globally, an estimated 570,000 women are newly diagnosed with cervical cancer, and 311,000 women die every year, with approximately $90 \%$ of the cases occurring in low- and middle-income countries (LMICs). Cervical cancer is the most common cancer in women in Cambodia, with age-standard incidence rate of 13.5/100,000 and mortality rate of 10.1/100,000. This paper introduces the educational and managerial interventions of Cambodia Cervical Cancer Project 2015-2018 by two professional societies of Cambodia and Japan. It can be categorized into three phases: health education and screening; diagnosis and treatment of precancerous lesions; and pathology service. Human papillomavirus test-based cancer screening and treatment of precancerous lesions were successfully initiated. Key factors contributed to optimal outcomes are partnership between two professional societies with strong commitment, and a comprehensive and stepwise quality-focused approach. A complementary role and joint society initiatives is a novel approach and substantial in sustainability for developing a system of cervical cancer management. This effort might serve as a good example how professional societies can contribute to capacity building and system development for prevention and control of cancer in LMICs.
\end{abstract}

Keywords: cervical cancer, screening and treatment, human papillomavirus test, professional society

\section{Introduction}

Globally, an estimated 570,000 women are newly diagnosed with cervical cancer, and 311,000 women die every year, with approximately $90 \%$ of the cases occurring in low- and middle-income countries (LMICs) (1). Since the main cause of cervical cancer is the persistent infection of high-risk subtypes of human papillomavirus (HPV), this cancer is largely preventable through primary prevention with the HPV vaccine and health education as well as secondary prevention with screening and treatment of precancerous lesions (2). These effective primary and secondary prevention measures are still not accessible to the majority of women in LMICs, and cervical cancer is identified only at an advanced stage, resulting in a high associated rate of death in these countries.

In Cambodia, with a female population of 8.2 million, cervical cancer is the most common cancer in women. The age-standard incidence rate (13.5 per 100,000 women) and mortality rate (10.1 per 100,000 women) are much higher than regional and global estimates (3). With an urgent need for action, cervical cancer was elevated to a disease to be given priority in the National Strategy for the Prevention and Control of Non-communicable Diseases (NCDs) 2007-2010 (4). In 2008, the Cambodian Ministry of Health (MOH) issued a national guideline for cervical cancer screening with visual inspection with acetic acid (VIA) and immediate treatment with cryotherapy (i.e., "screen and treat") as the nationwide strategy, followed by the national strategic plan for NCDs 2013-2020 (5).

Despite these efforts, the "screen and treat" strategy was still barely accessible to most women in Cambodia in 2015. Pilot programs were run with the support of different nongovernment organizations (NGOs), where 
VIA was used for screening at clinics and health centers, with the referral of positive screens to district hospitals for cryotherapy (6). None of the programs were successful in scaling up due to the lack of collaboration in harmonizing clinical practice. Recently, the HPV test has become more affordable with its higher accuracy and more objective endpoint than other screening methods (i.e., VIA or cytology) (7). However, its implementation is observed only in a few resource-limited countries (8).

The Cambodian Society of Gynecology and Obstetrics (SCGO) is the only society of professional obstetricians and gynecologists in Cambodia, established in 1997, with approximately 180 members as of 2015. With a request from the $\mathrm{MOH}$, the SCGO was eager to address the issue of limited access to screening and treatment but needed technical support. The SCGO and the Japan Society of Obstetrics and Gynecology (JSOG) initiated a collaborative project - Cambodia Cervical Cancer Project- in 2015.

In this paper, we introduce the educational and managerial interventions of Cambodia Cervical Cancer Project conducted by the SCGO and JSOG. This may serve as a good example of how professional societies can contribute to capacity building and system development for prevention and control of cancer in LMICs.

\section{Key interventions and primary outcomes of Cambodia Cervical Cancer Project}

This project was designed based on the WHO's guide to Comprehensive Cervical Cancer Control (2). It can be categorized into three project phases. Phase A (2015-2018) aimed to raise awareness of women's health and access to cervical cancer screening among factory workers; phase B (2015-2018) aimed to improve gynecologic capacity for the diagnosis and treatment of precancerous lesions; and phase C (2017-present) aimed to strengthen the pathological capacity for cancer diagnosis.

Table 1 summarizes the characteristics of each phase, and presents key educational and managerial interventions conducted at the individual, organizational, and systematic levels.

\section{Phase A (Health education and screening)}

Factory workers were selected for the target population because of the rapid increase in the number and social demand for their health and welfare in Cambodia (9). To assess baseline knowledge, attitude, and practice of the target population regarding reproductive health and cervical cancer, a cross-sectional survey was conducted in Factory A in March 2016. Among 443 female workers, their level of knowledge of women's health and cervical cancer was low. Approximately 85\% reported that their sources of information were relatives or friends, indicating that they rarely have opportunities to receive accurate knowledge from health professionals (10). Based on their educational needs, teaching materials on cervical cancer were developed.

The first health education session was held at Factory A in August 2016. Through sharing of the activities among factories in the Special Economic Zone, health education was expanded to other factories. The educational contents ultimately included five themes: basic hygiene, women's health, birth spacing, care during pregnancy and cervical cancer.

In parallel with health education, cervical cancer screening was offered on site to minimize the geographic access barrier to screening. The HPV test (careHPV ${ }^{\circledR}$, QIAGEN) was used because of its higher accuracy, more objective endpoint, and limited pathological capacity in the country $(7,11)$. With no reliable data on HPV infection in Cambodia, the eligibility criteria for screening were determined to be those who attended the health education program, who were over age 25 years old, who had ever had a sexual partner and who were not pregnant. Informed consent was obtained before the screening. Participants received group counseling after screening on the follow-up procedure as needed.

The collected cervical samples were sent to one of the national hospital laboratories where trained technicians performed the HPV assay. They became competent handling the HPV assay after one-month training with sufficient proficiency confirmed by a control laboratory in Japan (12). For women who tested positive, considering the risk of overtriage (13), a follow-up examination was scheduled at one of the target hospitals for Phase B.

Between August 2016 and May 2018, health education was conducted 14 times at five factories by a mobile team of midwives, SCGO gynecologists and SCGO secretariat staff. A total of 2,597 workers, including men, participated, and 687 women were eligible for screening. A mobile cervical cancer screening was conducted for the first time in Cambodia in the economic zone in June 2017, with a second round in April 2018. Among eligible women, 132 participated (screening rate 19.2\%) in two rounds of screening, and 15 had positive HPV results (HPV positivity rate $11.4 \%$ ).

Phase B (Diagnosis and treatment of precancerous lesions)

Situational analysis to examine the current practice at the target hospitals in November 2015 found that machines for diagnosis (colposcopy) and treatment of precancerous lesions (loop electrosurgical excision procedures (LEEP)) were already installed in all three hospitals but were often used improperly. Records regarding the number of abnormal cases detected and treated were poorly recorded (14).

To improve the skill of colposcopy and LEEP, a 


\section{Table 1. Characteristics and a summary of interventions in three project phases}

\begin{tabular}{|c|c|c|c|}
\hline Project Phase & $\begin{array}{c}\text { Phase A (Health education and } \\
\text { screening) }\end{array}$ & $\begin{array}{c}\text { Phase B (Diagnosis and treatment of } \\
\text { precancerous lesions) }\end{array}$ & Phase C (Pathology service) \\
\hline Objective & $\begin{array}{l}\text { Raise awareness of women's health } \\
\text { and access to cervical cancer } \\
\text { screening }\end{array}$ & $\begin{array}{l}\text { Improve gynecologic capacity for } \\
\text { diagnosis and treatment of precancer } \\
\text { lesions }\end{array}$ & $\begin{array}{l}\text { Strengthen pathological capacity for } \\
\text { cancer diagnosis }\end{array}$ \\
\hline Period & 2015-2018 & 2015-2018 & 2017-present \\
\hline \multicolumn{4}{|l|}{ Targets } \\
\hline Individual level & Factory workers and managers & Gynecologists and laboratory technicians & Pathologists and pathology technicians \\
\hline Organizational level & Five PPSEZ-based factories & Three national hospitals & $\begin{array}{l}\text { Three national hospitals and one national } \\
\text { hospital }\end{array}$ \\
\hline Funding agency ${ }^{\mathrm{a}}$ & JICA, MHLW & JICA, MHLW & MHLW \\
\hline $\begin{array}{l}\text { Implementing } \\
\text { organizations }\end{array}$ & SCGO, JSOG, NCGM & SCGO, JSOG, NCGM & SCGO, JSCC, NCGM \\
\hline Budget & \multicolumn{2}{|c|}{ Total USD 534,000 for 3 years for phase A and phase B } & USD 90,000/year \\
\hline $\begin{array}{l}\text { Interventions at } \\
\text { individual level }\end{array}$ & $\begin{array}{l}<\text { Factory workers }> \\
\text { - KAP survey on women's health } \\
\text { - Health education on women's } \\
\text { health } \\
\text { - Cervical cancer screening, early } \\
\text { diagnosis and treatment (as needed) } \\
<\text { Factory managers }> \\
\text { - Advocacy for raising awareness on } \\
\text { cervical cancer and women's health } \\
\text { - Feedback on the results of the } \\
\text { programs } \\
\text { - Discussions on ways to maintain } \\
\text { healthy workforce }\end{array}$ & $\begin{array}{l}<\text { Gynecologists }> \\
\text { - Training on the management of } \\
\text { cervical cancer screening program } \\
\text { (notice-screening-reporting-monitoring) } \\
\text { - Technical training on the collection of } \\
\text { cervical sample for HPV testing } \\
\text { - Technical training on diagnosis by } \\
\text { colposcopy and treatment by LEEP } \\
\text { - On-site training for implementation of } \\
\text { standard protocols } \\
<\text { Laboratory technicians }> \\
\text { - Technical training on the use of HPV } \\
\text { testing platform }\end{array}$ & $\begin{array}{l}<\text { Pathologists }> \\
\text { - Lectures on pathological diagnosis } \\
\text { - Discussions on ways to strengthen } \\
\text { pathology service in Cambodia (establishment } \\
\text { of a society, training of technicians, etc.) } \\
\text { - Provision of opportunities to be trained } \\
\text { abroad to learn how well-developed } \\
\text { pathology service and educational system } \\
\text { could look like } \\
<\text { Pathology technicians }> \\
\text { - Technical training on preparation of } \\
\text { quality pathology slides }\end{array}$ \\
\hline $\begin{array}{l}\text { Interventions at } \\
\text { organizational level }\end{array}$ & $\begin{array}{l}<\text { PPSEZ Secretariat }> \\
\text { - Reporting of the activities and } \\
\text { outcomes of the KAP survey, health } \\
\text { education and cervical cancer } \\
\text { screening programs } \\
<\text { Target factories }> \\
\text { - Provision of educational training to } \\
\text { the medical office staff }\end{array}$ & $\begin{array}{l}<\text { Target hospitals }> \\
\text { - Provision of LEEP instruments } \\
\text { - Provision of equipment and supplies } \\
\text { for HPV testing } \\
\text { - Development of hospital-level cervical } \\
\text { cancer registry } \\
\text { - Implementation of bar-code system for } \\
\text { lab sample management }\end{array}$ & $\begin{array}{l}<\text { Target hospitals }> \\
\text { - Promotion of good working environment } \\
\text { (ventilation, temperature management, } \\
\text { etc.) } \\
\text { - Development of standard operation } \\
\text { procedure for pathology slide preparation }\end{array}$ \\
\hline $\begin{array}{l}\text { Interventions at } \\
\text { network/policy level }\end{array}$ & $\begin{array}{l}\text { - Development of teaching materials } \\
\text { and brochures on cervical cancer } \\
\text { - Development of a health education } \\
\text { program on cervical cancer and } \\
\text { women's health } \\
\text { - Sharing of the program activities } \\
\text { to other PPSEZ-based factories at } \\
\text { regular meetings } \\
\text { - Sharing of program activities to } \\
\text { a wider audience through SCGO } \\
\text { website and SNS }\end{array}$ & $\begin{array}{l}\text { - Development of protocols for cervical } \\
\text { cancer screening } \\
\text { - Development of protocols and a } \\
\text { reference book for early diagnosis and } \\
\text { treatment of cervical cancer } \\
\text { - Provision of continuing professional } \\
\text { development through annual SGCO and } \\
\text { JSOG conferences, seminars, lectures, } \\
\text { and clinico-pathological conferences } \\
\text { - Reporting of the activities and } \\
\text { outcomes of the project to the Ministry } \\
\text { of Health }\end{array}$ & $\begin{array}{l}\text { - Educational support of pathology post- } \\
\text { graduate residency program } \\
\text { - Provision of continuing professional } \\
\text { development through clinico-pathological } \\
\text { conferences }\end{array}$ \\
\hline
\end{tabular}

${ }^{a}$ Exchange rate for calculation: 1 USD = 110 JPY. JICA: Japan International Cooperation Agency; JSCC: Japanese Society of Clinical Cytology; JSOG: Japan Society of Obstetrics and Gynecology; MHLW: Japanese Ministry of Health, Labour and Welfare; NCGM: National Center for Global Health and Medicine, Japan; PPSEZ: Phnom Penh Special Economic Zone; SCGO: Cambodian Society of Gynecology and Obstetrics; KAP: knowledge, attitudes, and practices; LEEP: Loop Electrosurgical Excision Procedure; SNS: social networking services.

series of hands-on trainings was conducted both on-site and in Japan between 2015 and 2018. LEEP was favored over cryotherapy for the treatment of precancerous lesions because it allows the lesions to be pathologically examined for definitive diagnosis and improves surgical capacity at tertiary hospitals responsible for cancer care. To harmonize practice, a standard clinical protocol was developed to guide clinical decision-making, and it was reviewed and revised after a year. Reporting forms and a registry for HPV-positive cases were also developed for monitoring.

In total, 13 physicians from three national hospitals were trained to acquire adequate skills in colposcopy and LEEP by 39 JSOG member physicians from 14 universities. Among the four who screened positive from the first round of screening in June 2017, none came 
for follow-up appointments. In addition to discussion with factory managers to allow sick leave, a call-andrecall system was introduced in the second round in April 2018, where SCGO secretarial staff made calls to those who screened positive to remind them to come for a follow-up and to respond to any concerns they had (15). The participation rate increased to $54.5 \%$ (six out of 11). Project outcomes were shared with the $\mathrm{MOH}$, society members, WHO and NGOs in the dissemination seminar in September 2018. HPV test-based screening was recognized as a possible option in Cambodia.

\section{Phase C (Pathology service)}

Through phase B, the obstacle to scaling up a cervical cancer screening program in Cambodia was identified as an extremely limited capacity for pathological services. When any screening program is scaled up in a country, there will inevitably be a large increase in the detection rate of cervical cancer. In 2017, however, there were only four pathologists and 15 pathology technicians actively working in the whole country. The situation was even worse than in 2014 because of the retirement of older generations (16).

At the target hospitals, although basic pathology equipment and supplies were available, slides were often difficult to read due to inadequate preparation. Stepby-step training was offered to technicians for quality slide preparation. Five pathology residents, enrolled in the national residency program that started in 2015 to increase the number of pathologists, were also trained for their capacity-building in diagnosis and quality management (17).

Under the initiative of the SCGO, a clinicopathological conference (CPC) was introduced to improve case management (17). In the beginning, pathologists and gynecologists tended to criticize each other on discrepancies between clinical and pathological diagnoses, but with close mentoring by Japanese physicians, a mutual learning environment was soon created. The CPC has gradually become a routine practice for developing clinical management skills.

The cooperation between professional societies contributes to capacity building and system development for cervical cancer prevention and control in Cambodia

Factors that contributed to optimal outcomes within a relatively small budget were identified from a series of focus group discussions and in-depth interviews during the project. Main factors are the partnership between two professional societies with strong ownership and commitment by the SCGO; and a comprehensive and stepwise quality-focused approach with stakeholder involvement

Since 1998, JSOG members have been working with the Cambodian $\mathrm{MOH}$ through development projects.
Individual collaboration became more institutional in 2012 when an exchange program was initiated between the JSOG and SCGO. The idea for this project came from the SCGO. Throughout the project implementation, the JSOG respected the initiative of the SCGO and adopted a coaching style to provide technical and managerial guidance as a professional society that has a public responsibility. The SCGO took this opportunity to develop institutional capacity and leadership and attracted over 300 physicians across the country in 2018.

A complementary role and joint society initiatives could contribute to moving activities forward. Achieving a goal as a joint activity between professional societies is a somewhat novel approach. Their moral authority as national professional societies can lead to building both ownership and leadership. This approach could be a key factor in sustainability for developing a system for cervical cancer management.

Quality is essential for cancer care. The stepwise quality-focused approach taken in this project revealed opportunities and barriers in each step of the comprehensive cancer care continuum. Solutions to address the barriers were discussed and responded to on time, such as a low participation rate of screening to the modification of teaching materials and adoption of the call-recall system.

Since the call for action to end the suffering caused by cervical cancer by the Director General of WHO in May 2018, countries and partners are working on developing a global strategy towards the elimination of cervical cancer (18). A wide-scale awareness campaign to create knowledge as well as demand for screening is usually used for scaling up intervention. Before the potential demand is created, service availability for screening, diagnosis and treatment, i.e., a capable workforce and functioning medical device, need to be in place. The small sample of intervention at the national level limits the reliability of application, especially with a capable workforce. However, in any level of service delivery, capacity building of service providers can be facilitated in a cascading manner by the SCGO under collaboration with the JSOG.

In conclusion, cooperation between $\mathrm{SCGO}$ and JSOG was the key for practice of the Cervical Cancer Prevention and Control Program in Cambodia. Contributing factors are based on joint society initiatives and a step-wise quality-focused approach. This effort might serve as a good example of how professional societies can contribute to capacity building and system development for prevention and control of cancer in LMICs.

\section{Acknowledgements}

The authors acknowledge SCGO and JSOG members who participated in the project for their contribution and cooperation. Authors also acknowledge Prof. Gilbert 
Burnham, Johns Hopkins Bloomberg School of Public Health, for his support for elaborating the manuscript.

Funding was obtained from Japan International Cooperation Agency and Japanese Ministry of Health, Labor and Welfare. The funders have no role in decision to publish and preparation of the manuscript.

\section{References}

1. Ginsburg O, Bray F, Coleman MP, et al. The global burden of women's cancers: a grand challenge in global health. Lancet. 2017; 389:847-860.

2. World Health Organization. Comprehensive cervical cancer control: a guide to essential practice - Second edition. https://www. who.int/reproductivehealth/ publications/cancers/cervical-cancer-guide/en/ (accessed January 4, 2020)

3. Ferlay J, Ervik M, Lam F, C et al. Global Cancer Observatory: Cancer Today. Lyon, France: International Agency for Research on Cancer. 2018. https://gco.iarc. fr/today/data/factsheets/populations/116-cambodia-factsheets.pdf (accessed 24 Jan, 2020)

4. Ministry of Health Cambodia. National Strategy for the Prevention and Control of Noncommunicable Disease 2007-2010. https://www.ghdonline.org/uploads/ Cambodia_NCD_Strategy_2007-10.pdf (accessed January 4, 2020)

5. Ministry of Health Cambodia. National Strategic Plan for the Prevention and Control of Noncommunicable Diseases 2013-2020. https://www.iccp-portal.org/system/files/ plans/KHM_B3_NSP-NCD\%202013-2020_Final\%20 approved.pdf (accessed January 4, 2020)

6. Thay S, Peprah SA, Hur C, Tramontano AC, Maling E, Goldstein AT, Hong C. Prevalence of Cervical Dysplasia in HIV-Positive and HIV-Negative Women at the Sihanouk Hospital Center of HOPE, Phnom Penh, Cambodia. Asian Pac J Cancer Prev. 2019; 20:653-659.

7. Mustafa RA, Santesso N, Khatib R, et al. Systematic reviews and meta-analyses of the accuracy of HPV tests, visual inspection with acetic acid, cytology, and colposcopy. Int J Gynaecol Obstet. 2016; 132:259-265.

8. World Health Organization. Assessing National Capacity for the Prvention and Control of Noncommunicable Diseases: Report of the 2017 Global Survey. 2018. https:// www.who.int/ncds/surveillance/ncd-capacity/en/ (accessed January 4, 2020)

9. United Nations Population Fund. Literature Review on Sexual and Reproductive Health and Rights of Migrant Garment Factory Workers in Cambodia. 2014. https:// cambodia.unfpa.org/sites/default/files/pub-pdf/SRHRofG armentFactoryWorkerLiteratureReview_2.pdf (accessed
January 4, 2020)

10. Cambodian Society of Gynecology and Obstetrics. SCGO-JSOG Project - Women's Health and Cervical Cancer-Introduction of the Project. 2015. http://scgo-kh. com/project-activities (accessed January 4, 2020)

11. Kelly H, Mayaud P, Segondy M, Pant Pai N, Peeling RW. A systematic review and meta-analysis of studies evaluating the performance of point-of-care tests for human papillomavirus screening. Sex Transm Infect. 2017; 93:S36-S45.

12. Ueda Y, Kawana K, Yanaihara N, et al. Development and evaluation of a cervical cancer screening system in Cambodia: A collaborative project of the Cambodian Society of Gynecology and Obstetrics and Japan Society of Obstetrics and Gynecology. J Obstet Gynaecol Res. 2019; 45:1260-1267.

13. Schiffman M, Castle PE. The promise of global cervicalcancer prevention. N Engl J Med. 2005; 353:2101-2104.

14. Kina U, Kanal K, Aun K, Soeung SC, Sim KL, Tharith S, Matsumoto Y, Obara H, Fijita N. Current situation of cervical cancer diagnosis, management and registration in three national tertiary hospitals in Cambodia. April 2016. Preseneted at the 68th Annual Congress of the Japan Society of Obstetrics and Gynecology, Tokyo Japan. http://www.jsog-oj.jp/detailAM.php?-DB=jsog\&LAYOUT $=$ am\&-recid $=17590 \&$-action $=$ browse $($ accessed January 24, 2020)

15. Ridsdale LL. Cervical screening in general practice: call and recall. J R Coll Gen Pract. 1987; 37:257-259.

16. Vathana CS, Stauch G. Pathology and telepathology in Cambodia. Pathology. 2014;46:S8

17. Akaba H, Fujita N, Stauch G, Matsumoto Y, Wakasa T, Kawahara K, Sawabe M, Kawai T. How can we strengthen pathology services in Cambodia? Global Health \& Medicine. 2019; 1:110-113.

18. World Health Organization. Accelerating cervical cancer elimination- Report by the Director-General. https:// apps.who.int/gb/ebwha/pdf_files/EB144/B144_28-en.pdf (accessed January 4, 2020)

Received January 8, 2020; Revised January 21, 2020; Accepted January $27,2020$.

Released online in J-STAGE as advance publication February 2, 2020.

*Address correspondence to:

Noriko Fujita, Bureau of International Health Cooperation, National Center for Global Health and Medicine, 1-21-1 Toyama Shinjuku-ku, Tokyo 162-8655, Japan.

E-mail: norikof@it.ncgm.go.jp 